\title{
Panax ginseng and salvia miltiorrhiza supplementation abolishes eccentric exercise-induced vascular stiffening: a double-blind randomized control trial
}

\author{
Hsin-Fu Lin ${ }^{1,6}$, Kang Tung ${ }^{2}$, Chun-Chung Chou ${ }^{3}$, Ching-Che Lin ${ }^{4}$, Jaung-Geng Lin ${ }^{5}$ and Hirofumi Tanaka ${ }^{6 *}$
}

\begin{abstract}
Background: Muscle damage induced by unaccustomed or eccentric exercise results in delayed onset vascular stiffening. We tested the hypothesis that a 7-day supplementation of panax ginseng and salvia miltiorrhiza prior to an acute eccentric exercise could attenuate arterial stiffening.

Methods: By using a double-blind study placebo-controlled randomized design, subjects were randomly assigned to either the Chinese herb $(N=12)$ or the placebo group $(N=11)$ and performed a downhill running (eccentric exercise) trial and a control (seated rest) trial.

Results: Muscle soreness increased 1-2 days after exercise similarly in both groups, whereas the herb group demonstrated a faster recovery on active range of motion. Plasma creatine kinase concentration increased significantly at $24 \mathrm{~h}$ in both groups but the magnitude of increase was attenuated in the herb group. Arterial stiffness as measured by carotid-femoral pulse wave velocity increased significantly at $24 \mathrm{~h}$ in the placebo group but such increase was absent in the herb group. Flow-mediated dilation did not change in either group. Plasma concentrations of CRP and IL-6 increased in the placebo group but no such increases were observed in the herb group. Changes in arterial stiffness induced by eccentric exercise were associated with the corresponding changes in $\mathrm{L}-6(r=0.46, P<0.05)$.
\end{abstract}

Conclusions: A short-term Chinese herb supplementation of panax ginseng and salvia miltiorrhiza ameliorated the delayed onset vascular stiffening induced by acute downhill running exercise.

Trial registration: ClinicalTrials.gov: NCT02007304. Registered Dec. 5, 2013)

Keywords: muscle damage, inflammation, arterial stiffness

\section{Background}

Muscle damage induced by unaccustomed or eccentric exercise is associated with increases in oxidative stress, inflammatory response, and delayed onset muscle soreness [1]. The increases in circulating pro-inflammatory cytokine and C-reactive protein (CRP) are the characteristic responses induced by eccentric exercise [2, 3]. A growing body of evidence indicates that muscle damage may also exert adverse influences on vascular function a day or two days later on a similar time frame to delayed

\footnotetext{
* Correspondence: htanaka@austin.utexas.edu

${ }^{6}$ Department of Kinesiology and Health Education, The University of Texas at Austin, 2109 San Jacinto Blvd, D3700, Austin, TX 78712, USA

Full list of author information is available at the end of the article
}

onset muscle soreness. An impairment in microcirculation $[4,5]$, an increase in vascular resistance [6], and a reduction in vascular reactivity $[7,8]$ have been observed after acute eccentric exercise. We [9] and others [10] have demonstrated that acute eccentric exercise induced significant increases in central arterial stiffness and arterial stiffening after eccentric exercise was associated with indicators of muscle damage [9].

In Chinese Medicine, Ginseng is one of the most commonly used herbs in over thousands of years [11]. Ginsenosides, the major compounds of ginseng, and its metabolites are considered to exert protective effects on the vasculature, acting as a free radical scavenger [12] and increasing nitric oxide production and antioxidant 
effects [13]. There have been a number of animal studies demonstrating that supplementation with either Asian ginseng (panax ginseng C. A. Meyer) or American ginseng (panax quinquefolium L.) could protect against eccentric or strenuous exercise-induced muscle damage by attenuating CK release $[14,15]$ and inflammatory responses [16]. Danshen (salvia miltiorrhiza) is another widely used Chinese medicinal herb with diverse pharmacological properties to improve circulation and blood stasis [17], including dilating coronary arteries, increasing blood flow, and scavenging free radicals in ischemic diseases [18]. Indeed danshen has been prescribed to treat angina pectoris, hyperlipidemia, acute ischemic stroke [19], and coronary heart disease [20]. The major compounds of danshen, Tanshinone IIA and salvianolical acid B, have been shown to suppress vasoconstrictor endothelin-1 production [21] and reduce the expression of vascular adhesion molecules in vitro [22, 23]. Panax ginseng and danshen are often mixed in herb formulas in Chinese medicine, which is characterized by adapting several types of herbs or minerals as a combination of multiple components that could synergistically attack different pathological targets [24]. Panax ginseng and danshen has been practiced as a formula to treat cardiovascular disease in Chinese Medicine $[24,25]$; however, scientific evidence to support its use is still lacking. In this study we tested the hypothesis that the supplementation with a combination of panax ginseng and danshen could exert protective effects on the vasculature following eccentric exercise.

\section{Methods}

\section{Participants}

A total of 24 apparently healthy young male adults surrounding by National Taiwan University community were recruited. Exclusions from the study participation were due to: (1) obesity (BMI $>30 \mathrm{~kg} / \mathrm{m}^{2}$ ); (2) smoking within past six months; (3) hypertension (high blood pressure $>140 / 90 \mathrm{mmHg}$ ); (4) personal history of diabetes (fasting blood glucose $>126 \mathrm{mg} / \mathrm{dL}$ ), history of heart disease or other cardiovascular problems; (5) orthopedic injury that may prevent him or her from completing the exercise; or (6) the use of over-thecounter supplements or vitamins. Subjects must have been sedentary or recreational active, but not been participating in any type of resistance or endurance training. All subjects gave their inform written consent prior to study participation and procedures were reviewed and approved by Institutional Review Board of National Taiwan University Hospital. This study is listed in ClinicalTrial.gov (NCT02007304).

\section{Experimental design}

Subjects were randomly assigned into either the Chinese herb supplement or the placebo group after pre-screening and familiarization. In each group, subjects underwent two familiarization sessions followed by a pre-testing session that consists of the measurements of aerobic power and body composition. Eccentric exercise trials took place following a 7-day supplementation. Subjects were asked to keep their regular diet and sedentary lifestyle throughout the testing sessions.

\section{Aerobic power}

Individual peak aerobic power $\left(\mathrm{VO}_{2}\right.$ peak $)$ was determined using standard American College of Sports Medicine protocol. After a 5-min warm-up on the treadmill, subjects walked or ran while treadmill slope was increased $1 \%$ every minute until the subjects could not continue the test. A mouthpiece and heart rate monitor were worn to collect expired air and assess heart rate throughout the test. $\mathrm{VO}_{2}$ peak was used to set the exercise intensity during the eccentric exercise.

\section{Body composition}

Percent body fat was measured noninvasively by using a bioimpedance analyzer Inbody 2.0 (Biospace Co. Ltd., Seoul, South Korea). To avoid the hydration effects, the test was performed in the morning when subjects were fasted.

\section{Supplement administration}

Following the pre-testing sessions, subjects were asked to take a total of 7 capsules of either Chinese herb or placebo per day for seven days. Herb supplement was prepared in capsules consisting of $250 \mathrm{mg}$ of panax ginseng and $250 \mathrm{mg}$ salvia miltiorrhiza via the water-extraction method, whereas placebo capsules contained microcrystalline cellulose. According to the pharmacopoeia of the People's Republic of China [26], the use of 1-3 $\mathrm{g}$ danshen extract per day is recommended [27]. A dosage of $1.75 \mathrm{~g}$ per day ( $\sim 60 \%$ of the maximal suggested dosage) was chosen for danshen in order to avoid unexpected adverse event and to take consideration that this was a combination herb therapy. To the best of our knowledge, a combination of panax ginseng and salvia miltiorrhiza together has not been investigated on humans in the literature [24]. Accordingly, we decided to adopt the 1:1 ratio (i.e., the same dosage) of panax ginseng and salvia miltiorrhiza as the supplementation. Similar to danshen, this particular dosage of panax ginseng has been shown to be effective. Hence, the total daily supplementation dosage was $3.5 \mathrm{~g}$ together.

Both Chinese herb and placebo capsules were identical in appearance and stored in identical bottles with labeled numbers generated by a study-independent researcher. All supplement products were prepared by the Brion Research Institute, Sun Ten Pharmaceutical Co. Analyses of ginsenosides of panax ginseng as well as Salvianolic acid B and 
Tanshinone IIA in Radix salvia miltiorrhiza were performed by using high-performance liquid chromatographyelectrospray mass (HPLC-MS) spectrometry method as previously described [26, 28]. These chromatographic quantification results of active compounds in herb supplement are shown in Table 1 and Fig. 1.

\section{Exercise protocol}

Subjects were instructed to fast at least $8 \mathrm{~h}$ and refrain from any strenuous exercise for at least $72 \mathrm{~h}$ before the test. Experimental trial consisted of baseline measurements, downhill running (eccentric exercise) or seated rest (control), and measurements during the recovery period. In order to eliminate diurnal variation of inflammatory response to eccentric exercise, participants were asked to perform both eccentric exercise and control trials at the same time of day. Subjects warmed up on treadmill on a level grade at the speed that could elicit $75 \%$ of predetermined individual $\mathrm{VO}_{2}$ peak [29] for $5 \mathrm{~min}$. Each subject performed downhill running exercise on treadmill with the same speed at $-10^{\circ}$ of slope for $30 \mathrm{~min}$. Similar protocols have been successfully used elsewhere to induce delayed onset muscle soreness [10,30].

\section{Measurements}

The measurements were made 5 times: 30 min pre, $90 \mathrm{~min}$ post, $24 \mathrm{~h}$ post, $48 \mathrm{~h}$ post, and $72 \mathrm{~h}$ post. Subjects were studied at the same time of day, during the morning hours to minimize the inconvenience of the 8$\mathrm{h}$ fast and to avoid diurnal effects.

Blood samples were collected to determine metabolic risk factors, markers of muscle damage, inflammation, and redox state. Serum CK was used as an indicator of muscle membrane permeability or muscle damage [31]. Inflammatory markers (TNF- $\alpha$, IL-6) as well as blood redox status marker, tiobarbituric acid-reactive substances (TBARS), were analyzed with the use of commercial ELISA kits. Due to the financial constraints, TNF- $\alpha$, IL-6, and TBARS were measured only in the eccentric exercise condition. The inter- and intra-assay coefficients of variation were less than $10 \%$ in all assays performed.

Heart rate and blood pressure were measured in the supine position. Heart rate was measured using an ECG,

Table 1 Quantitative analyses of major compounds of the herb supplement used in the present study

\begin{tabular}{lll}
\hline & Compound & Content $(\mathrm{mg} / \mathrm{g})$ \\
\hline Panax ginseng & $\mathrm{Rb} 1$ & 2.24 \\
& $\mathrm{Re}$ & 1.13 \\
& $\mathrm{Rg} 1$ & 1.47 \\
Salvia miltiorrhiza & Salvianolia acid B & 28.2 \\
& Tanshinone IIA & 0.6 \\
\hline
\end{tabular}

and blood pressure was measured using an automatic blood pressure monitor (Omron HEM907).

\section{Muscle soreness}

Subjects were asked to rate the perception of muscle soreness using a Visual Analog Scale of 0-10 with 0 describing no soreness and 10 describing unbearable soreness immediately after a downhill running [32]. In addition, active range of motion was measured while the subjects were placed on bed in prone position with full knee extension and then moved both legs gradually to the flexion point where pain in quadriceps muscle groups was experienced. A manual goniometer was used to measure the knee angle difference from full extension to flexion point with the initiation of pain. This test was repeated three times, and the average was used for statistical analysis.

\section{Arterial stiffness}

Arterial stiffness was measured using carotid-femoral pulse wave velocity (cfPWV), which was calculated from the traveling distance and foot-to-foot wave transit time between the two arterial recording sites in the supine position [33], and was the primary outcome measure of this study. Non-invasive pulse tonometer (SPT-301, Millar Inc. Houston TX) connected to a physiological signaling processing system (MP36, Biopac, Goleta CA) was used to detect pulse waves on the carotid and femoral arteries. The coefficient of variation for cfPWV in our laboratory were $6.2 \%$.

\section{Vascular reactivity}

Flow-mediated dilatation, the secondary outcome measure, was obtained noninvasively at the brachial artery using standardized procedure [34]. Brachial artery diameter was measured using an ultrasound machine (Sonosite Ultrasound System; Bothell, WA) equipped with a highresolution linear array transducer. A blood pressure cuff was placed on the forearm 3-5 cm distal to the antecubital fossa, and longitudinal images of the brachial artery were acquired 5-10 cm proximal to the antecubital fossa. After the acquisition of baseline measurement, the probe position was clearly marked to ensure that the image was acquired from the same location throughout the test. The blood pressure cuff was inflated to $100 \mathrm{mmHg}$ above resting systolic blood pressure for $5 \mathrm{~min}$ by using a customized rapid inflation system. After cuff deflation, ultrasound-derived measurements of artery diameters were taken for $3 \mathrm{~min}$. FMD was calculated by the following equation: (maximum diameter - baseline diameter)/ baseline diameter $\times 100$. All ultrasound images were recorded and analyzed by the same investigator who was blinded to the groups and the conditions. Our coefficient 


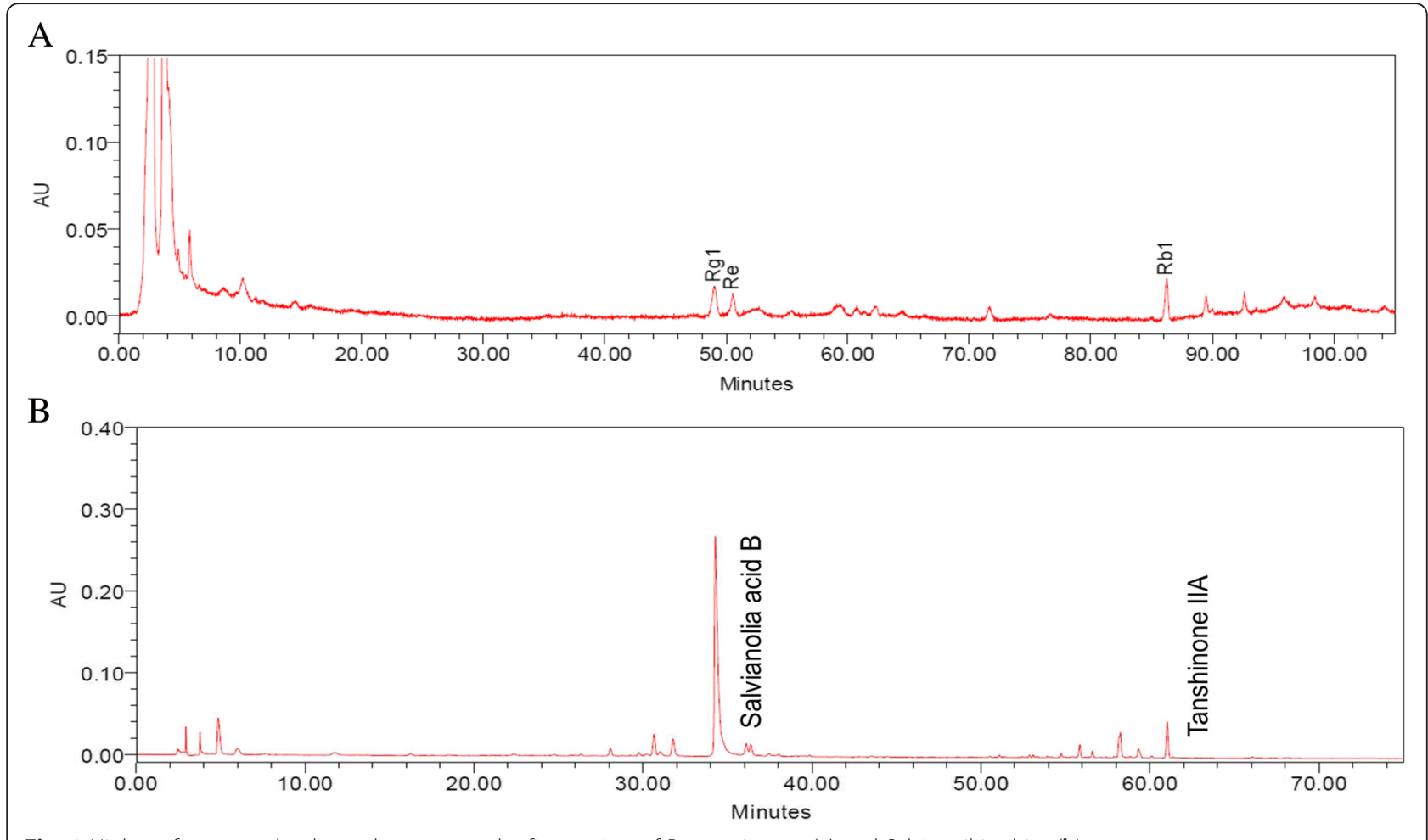

Fig. 1 High-performance thin-layer chromatography fingerprints of Panax ginseng (a) and Salvia miltiorrhiza (b)

of variation of baseline diameter, maximal diameter, and FMD in our laboratory were $3.7,4.0$, and $14 \%$.

\section{Randomization and blinding}

Allocation to the herb or placebo supplementation was based on a computer-generated randomization list that was prepared by a study-independent researcher. Blockrandomization with a block size of four was used; the group assignment was concealed in an envelope and revealed after all data analysis was performed. During study, researchers were blinded and unaware of subjects' allocation. Subjects were instructed not to reveal any information regarding supplement and exercise treatment during intervention.

\section{Statistical analyses}

Descriptive statistics were used for the analyses of subject characteristics using SPSS statistical package (version 16.0; Chicago, IL). Dependent variables were analyzed within each treatment to determine the time effect (pre, $90 \mathrm{~min}$, $24 \mathrm{~h}, 48 \mathrm{~h}$, and $72 \mathrm{~h}$ post exercise) using repeated measures ANOVA. A 2-way mixed model ANOVA was used for analyses of time and treatment effects. Bonferroni post-hoc analysis was performed when significance was achieved. Associations were determined by Spearman rank correlations. To detect difference in cfPWV of $5 \%$ at a SD of $4.5 \%$ unit change with $80 \%$ power ( $\alpha$ was set at
0.05 ) and accounting for a $10 \%$ attrition rate, a total of 24 subjects were to be recruited and tested.

\section{Results}

After screening, twenty-four subjects were eligible and entered into the study (Fig. 2); one subject withdrew from the study during intervention due to time commitment unrelated to the study. Selected subject characteristics are presented in Table 2. All the subjects were non-obese, normolipidemic, and normotensive. There were no significant differences in body composition, lipid profile, and baseline hemodynamic parameters between the placebo and the Chinese herb groups.

An acute bout of downhill running exercise increased muscle soreness significantly at $90 \mathrm{~min}, 24$ and $48 \mathrm{~h}$ post exercise (Fig. 3). Active range of motion decreased significantly at 24 and $48 \mathrm{~h}$ post exercise in both groups, but remained significant at $72 \mathrm{~h}$ in the placebo group (Fig. 3). As shown in Fig. 4, the magnitude of the increase in plasma CK concentration was significantly greater in the placebo group than in the herb group.

An acute bout of eccentric exercise increased cfPWV at $24 \mathrm{~h}$ post exercise in the placebo group (Fig. 5). No such significant increase in cfPWV was observed in the herb group. There were no changes in blood pressure in either group (Table 3). As shown in Fig. 6, there were no significant changes in FMD. 


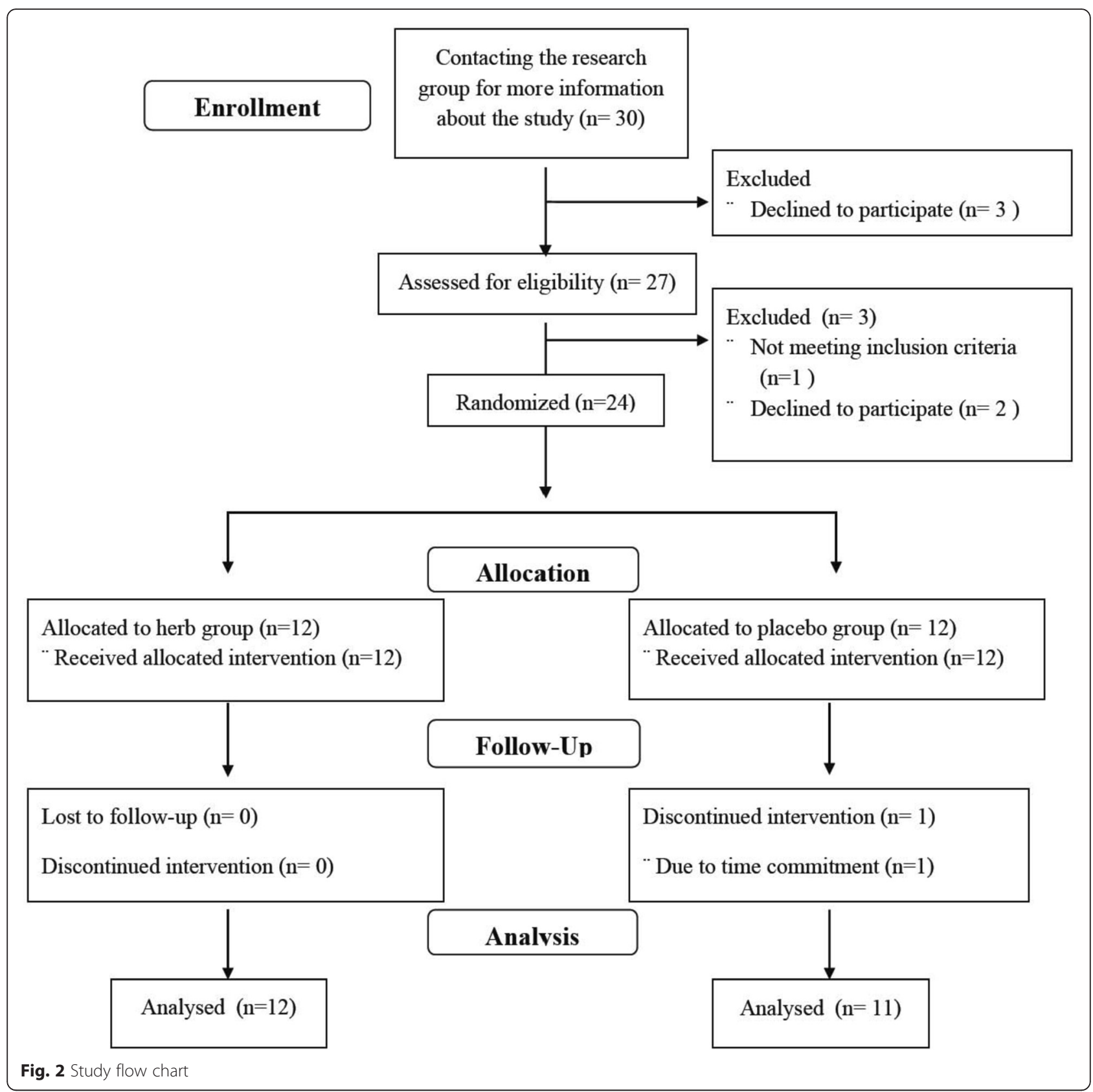

Plasma CRP concentration increased significantly at $24 \mathrm{~h}$ post eccentric exercise in both groups (Table 4). Plasma TBARs and TNF- $\alpha$ concentrations did not change in either group. Plasma IL-6 concentration increased significantly at $90 \mathrm{~min}$ after eccentric exercise in the placebo group.

The associations between changes in cfPWV and changes in selected biomarkers in combined groups are shown in Table 5. Changes in IL-6 were associated with changes in cfPWV at $48 \mathrm{~h}$ post exercise $(r=0.46$, $P<0.05)$. In addition, changes in TNF- $\alpha$ were associated with changes in cfPWV at 24 to $48 \mathrm{~h}$ after exercise $(r=0.57 \sim 0.60, P<0.05)$.

\section{Discussion}

The major findings of this study are as follows. Seven days of herb supplementation of panax ginseng and salvia miltiorrhiza prior to downhill running exercise did not affect muscle soreness, but prevented the significant and transient increase in arterial stiffness, and facilitated the recovery of active range of motion induced by muscle damage. This "destiffening" effect was independent of blood 
Table 2 Selected subject characteristics

\begin{tabular}{lll}
\hline & Placebo & Herb \\
& $(n=11)$ & $(n=12)$ \\
\hline Age, yr & $24 \pm 1$ & $26 \pm 5$ \\
Height, cm & $173 \pm 1$ & $174 \pm 3$ \\
Body mass, kg & $68 \pm 2$ & $68 \pm 3$ \\
BMl, kg/m² & $23 \pm 1$ & $22 \pm 1$ \\
Body fat percentage, \% & $19 \pm 1$ & $18 \pm 2$ \\
Waist-hip ratio & $0.85 \pm 0.01$ & $0.85 \pm 0.01$ \\
Heart rate at rest, bpm & $67 \pm 3$ & $58 \pm 3$ \\
Systolic BP, mmHg & $118 \pm 2$ & $112 \pm 3$ \\
Diastolic BP, mmHg & $66 \pm 2$ & $62 \pm 2$ \\
VO ${ }_{2}$ peak, ml/kg/min & $47 \pm 2$ & $47 \pm 2$ \\
HDL cholesterol, mg/dL & $53 \pm 2$ & $53 \pm 3$ \\
LDL cholesterol, mg/dL & $97 \pm 9$ & $86 \pm 5$ \\
Total cholesterol, mg/dL & $180 \pm 9$ & $192 \pm 8$ \\
Triglyceride, mg/dL & $78 \pm 9$ & $58 \pm 8$ \\
HbA1C, \% & $5.4 \pm 0.1$ & $5.4 \pm 0.1$ \\
\hline Valus ar means \pm SEM & &
\end{tabular}

Values are means \pm SEM

$B M I$ body mass index, $B P$ blood pressure, $\mathrm{VO}_{2}$ peak peak oxygen consumption, HbA1c glycosylated hemoglobin A1c

pressure changes as arterial pressure did not change in either group. A lack of changes in arterial stiffness with the herb supplementation was in part associated with the attenuated increases in inflammatory markers. These results suggest that the Chinese herb supplementation may be an effective strategy to minimize the delayed onset vascular stiffening induced by eccentric exercise.

The presence of elevated plasma CK has been recognized a marker of increased sarcolemma permeability or muscle damage resulted from unaccustomed exercise or eccentric muscle contractions [31, 35, 36]. In the present study, an acute bout of downhill running exercise increased plasma CK concentration significantly following eccentric exercise. The increase in plasma CK concentration was greater in the placebo group at $24 \mathrm{~h}$ post exercise than in the herb group. Previous studies in animal models reported that North American ginseng, panax ginseng or panax quinquefolus, decreased plasma CK levels after eccentric exercise $[15,37]$ and preserved mitochondria integrity [14] and decreased macrophage infiltration [16] in skeletal muscle. One recent human study [38] also found that American ginseng decreased $\mathrm{CK}$ concentration at $72 \mathrm{~h}$ post exercise when compared with the placebo control. Collectively, these results suggest that Chinese herb supplementation may have reduced the amount of muscle damage induced by eccentric exercise.

In the present study, arterial stiffening effects were attenuated when the subjects were supplemented with Chinese herbs for 7 days before the unaccustomed exercise was performed. These effects were not related to changes in blood pressure in either group. To our knowledge, this is the first study to demonstrate that Chinese herb supplementation effectively prevented the adverse effects on vascular stiffening induced by eccentric exercise. Specifically, downhill running increased arterial stiffness significantly as early as $24 \mathrm{~h}$ after the eccentric exercise in the placebo group. In the previous study [10] including ours [9], the increase in arterial stiffness was somewhat delayed showing up at $48 \mathrm{~h}$ after exercise. The exact reasons for the slight differences in the time course are not known. But compared with our previous study [9] that used localized resistance exercise as an eccentric stimulus, in the present study, we used more systemic downhill running exercise that elicit greater and more robust responses [39]. Moreover, compared with the previous study that utilized moderately-trained young adults [10], the subjects in the current study were mainly sedentary adults. Current literature indicates that people who repeatedly perform eccentric muscle contractions demonstrate so-called "repeated bout effect" or adaptation in skeletal muscle that inflammatory and muscle biomarker responses were substantially lowered in the
A

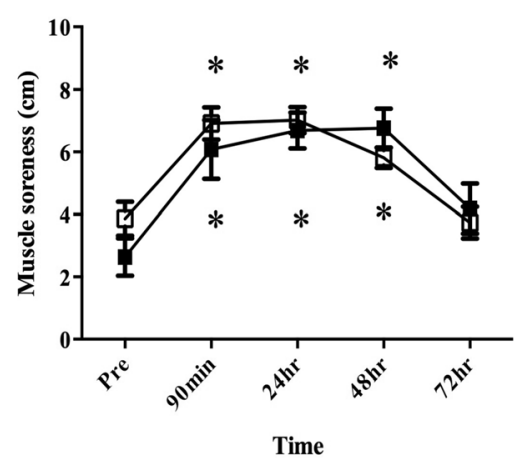

B

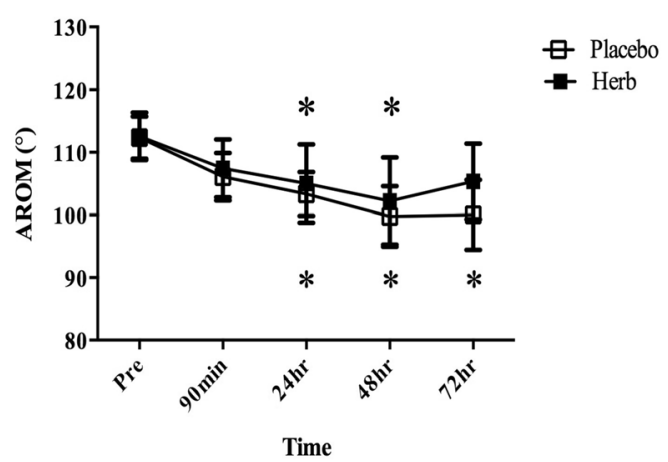

Fig. 3 Delayed onset muscle soreness (a) and active range of motion (AROM) (b) following downhill running exercise. ${ }^{*} P<0.05$ vs. Pre in the same condition 


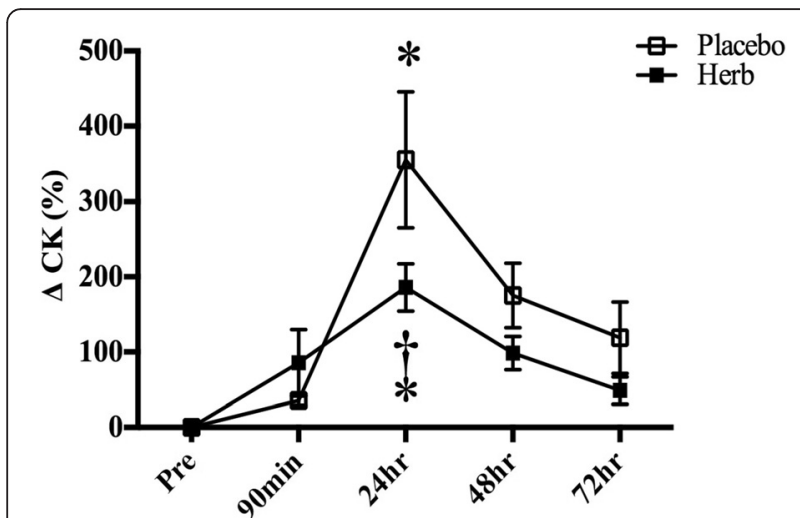

Fig. 4 Relative changes in serum creatine kinase (CK) concentration in response to eccentric exercise sessions. ${ }^{*} P<0.05$ vs. Pre in the same condition. $+P<0.05$ vs. Placebo at the same time point

following challenge [1], suggesting that exercise training status plays a role in determining the response to this exercise challenge.

The underlying mechanisms by which muscle damage induced by eccentric exercise results in increased arterial stiffness remain unclear. However, arterial stiffening following eccentric exercise has been associated with increases in subjective muscle soreness [10], a marker of muscle damage (i.e., plasma CK) [9]. In the present study, plasma IL-6 levels increased significantly after eccentric exercise in the placebo group. Previous studies have demonstrated that the acute inflammation induced by a vaccination increased not only IL- 6 and CRP concentrations [40, 41] but also arterial stiffness [42]. Collectively, these results suggest that arterial stiffening induced by muscle damage is associated with markers of muscle damage and/or systemic inflammation.

Consistent with this concept, we found that Chinese herb supplementation minimized the increases in IL-6 levels. Additionally, changes in arterial stiffness were
Table 3 Hemodynamic responses in control (seated rest) and eccentric exercise sessions

\begin{tabular}{|c|c|c|c|c|c|c|}
\hline \multirow{2}{*}{\multicolumn{2}{|c|}{$\overline{c f P W V}, \mathrm{~cm} / \mathrm{s}$}} & Pre & $90 \mathrm{~min}$ & $24 \mathrm{~h}$ & $48 \mathrm{~h}$ & $72 \mathrm{~h}$ \\
\hline & & & & & & \\
\hline \multirow[t]{2}{*}{ Placebo } & Control & $530 \pm 19$ & $535 \pm 17$ & $546 \pm 16$ & $547 \pm 15$ & $513 \pm 13$ \\
\hline & Exercise & $531 \pm 12$ & $548 \pm 19$ & $577 \pm 20^{*}$ & $570 \pm 24$ & $552 \pm 22$ \\
\hline \multirow[t]{2}{*}{ Herb } & Control & $482 \pm 14$ & $491 \pm 17$ & $490 \pm 14$ & $487 \pm 13$ & $505 \pm 19$ \\
\hline & Exercise & $523 \pm 20$ & $497 \pm 17$ & $503 \pm 16$ & $500 \pm 13$ & $505 \pm 23$ \\
\hline
\end{tabular}

Heart rate, bpm

\begin{tabular}{lcccccc} 
Placebo & Control & $63 \pm 4$ & $58 \pm 3$ & $62 \pm 3$ & $66 \pm 3$ & $65 \pm 3$ \\
& Exercise & $62 \pm 3$ & $69 \pm 4^{*}$ & $66 \pm 3$ & $63 \pm 3$ & $59 \pm 5$ \\
Herb & Control & $57 \pm 3$ & $54 \pm 1$ & $56 \pm 3$ & $59 \pm 4$ & $55 \pm 3$ \\
& Exercise & $56 \pm 2$ & $65 \pm 4^{*}$ & $56 \pm 3$ & $55 \pm 2$ & $53 \pm 3$ \\
\multicolumn{2}{l}{ Systolic BP, mmHg } & & & & & \\
Placebo Control & $119 \pm 2$ & $116 \pm 2$ & $118 \pm 2$ & $119 \pm 2$ & $119 \pm 2$ \\
& Exercise & $119 \pm 2$ & $114 \pm 2$ & $120 \pm 2$ & $120 \pm 3$ & $117 \pm 2$ \\
Herb & Control & $114 \pm 2$ & $111 \pm 2$ & $114 \pm 2$ & $115 \pm 3$ & $115 \pm 2$ \\
& Exercise & $116 \pm 3$ & $114 \pm 3$ & $115 \pm 2$ & $112 \pm 2$ & $111 \pm 3$
\end{tabular}

Diastolic BP, $\mathrm{mmHg}$

\begin{tabular}{lcccccc} 
Placebo & Control & $66 \pm 2$ & $67 \pm 1$ & $67 \pm 2$ & $64 \pm 2$ & $67 \pm 2$ \\
& Exercise & $66 \pm 3$ & $65 \pm 2$ & $65 \pm 3$ & $66 \pm 2$ & $64 \pm 2$ \\
Herb & Control & $63 \pm 3$ & $63 \pm 1$ & $62 \pm 2$ & $62 \pm 1$ & $62 \pm 1$ \\
& Exercise & $63 \pm 3$ & $61 \pm 2$ & $62 \pm 1$ & $63 \pm 3$ & $60 \pm 1$ \\
\multicolumn{2}{c}{ Pulse pressure, $\mathrm{mmHg}$} & & & & \\
Placebo Control & $52 \pm 2$ & $49 \pm 1$ & $51 \pm 2$ & $55 \pm 2$ & $53 \pm 2$ \\
& Exercise & $53 \pm 2$ & $48 \pm 2$ & $55 \pm 2$ & $53 \pm 2$ & $53 \pm 1$ \\
Herb & Control & $51 \pm 3$ & $48 \pm 3$ & $52 \pm 3$ & $54 \pm 3$ & $53 \pm 3$ \\
& Exercise & $53 \pm 3$ & $52 \pm 3$ & $53 \pm 2$ & $49 \pm 3$ & $51 \pm 3$
\end{tabular}

Values are means \pm SEM

cfPWV carotid-femoral pulse wave velocity, $B P$ blood pressure

${ }^{*} P<0.05$ vs. Pre in the same condition

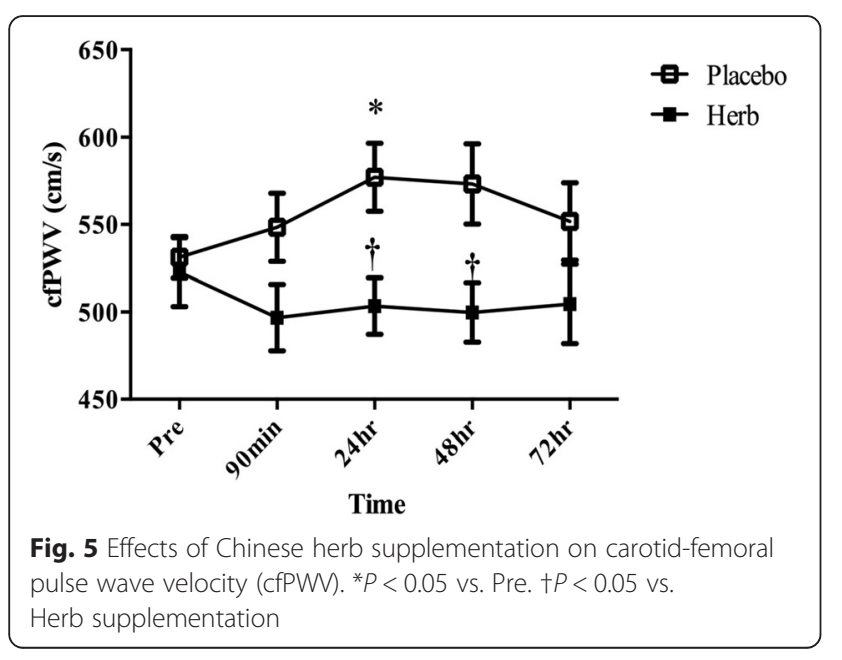

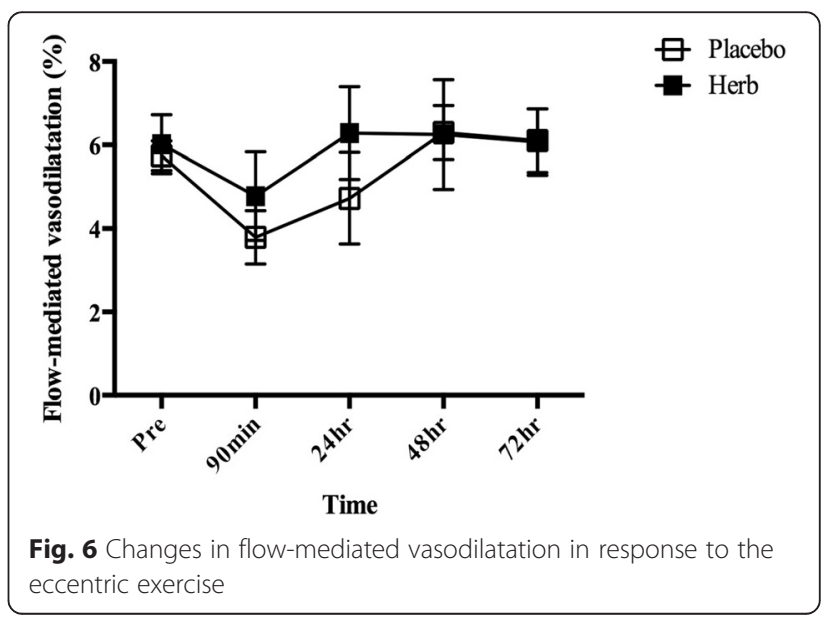


Table 4 Changes in muscle damage markers, inflammatory and oxidative stress markers in response to downhill running exercise in the placebo and herb group

\begin{tabular}{|c|c|c|c|c|c|}
\hline & Pre & $90 \mathrm{~min}$ & $24 \mathrm{~h}$ & $48 \mathrm{~h}$ & $72 \mathrm{~h}$ \\
\hline \multicolumn{6}{|l|}{ Placebo } \\
\hline \multicolumn{6}{|l|}{$\mathrm{CRP}, \mathrm{mg} / \mathrm{dL}$} \\
\hline Control & $0.07 \pm 0.04$ & $0.07 \pm 0.04$ & $0.07 \pm 0.03$ & $0.06 \pm 0.02$ & $0.05 \pm 0.02$ \\
\hline Exercise & $0.08 \pm 0.02$ & $0.11 \pm 0.05$ & $0.15 \pm 0.05^{*}$ & $0.11 \pm 0.05$ & $0.10 \pm 0.03$ \\
\hline \multicolumn{6}{|l|}{$\mathrm{CK}, \mathrm{U} / \mathrm{L}$} \\
\hline Control & $94 \pm 10$ & $98 \pm 8$ & $89 \pm 8$ & $87 \pm 9$ & $90 \pm 11$ \\
\hline Exercise & $93 \pm 8$ & $126 \pm 13$ & $396 \pm 72^{*}, * *$ & $257 \pm 48^{*}, * *$ & $192 \pm 32^{*}$ \\
\hline \multicolumn{6}{|l|}{ Herb } \\
\hline \multicolumn{6}{|l|}{$\mathrm{CRP}, \mathrm{mg} / \mathrm{dL}$} \\
\hline Control & $0.13 \pm 0.05$ & $0.14 \pm 0.05$ & $0.11 \pm 0.04$ & $0.11 \pm 0.04$ & $0.11 \pm 0.03$ \\
\hline Exercise & $0.10 \pm 0.03$ & $0.09 \pm 0.03$ & $0.15 \pm 0.03^{*}$ & $0.10 \pm 0.02$ & $0.10 \pm 0.02$ \\
\hline \multicolumn{6}{|l|}{$\mathrm{CK}, \mathrm{U} / \mathrm{L}$} \\
\hline Control & $110 \pm 12$ & $108 \pm 9$ & $119 \pm 17$ & $109 \pm 11$ & $113 \pm 16$ \\
\hline Exercise & $106 \pm 9$ & $195 \pm 51^{*}$ & $291 \pm 35^{*, * *}$ & $204 \pm 26^{*}, * *$ & $151 \pm 20$ \\
\hline \multicolumn{6}{|l|}{ TBARs, $\mu \mathrm{M}$} \\
\hline Placebo & $7.1 \pm 1.1$ & $8.1 \pm 1.5$ & $7.9 \pm 1.0$ & $6.5 \pm 1.0$ & - \\
\hline Herb & $7.0 \pm 1.0$ & $6.6 \pm 0.8$ & $8.1 \pm 0.9$ & $5.7 \pm 0.6$ & - \\
\hline \multicolumn{6}{|l|}{ IL-6, pg/ml } \\
\hline Placebo & $0.44 \pm 0.1$ & $0.69 \pm 0.1^{*}$ & $0.32 \pm 0.1$ & $0.46 \pm 0.1$ & - \\
\hline Herb & $0.50 \pm 0.2$ & $0.45 \pm 0.1$ & $0.23 \pm 0.1^{*}$ & $0.29 \pm 0.1$ & - \\
\hline \multicolumn{6}{|c|}{ TNF-a, pg/ml } \\
\hline Placebo & $0.45 \pm 0.14$ & $0.28 \pm 0.06$ & $0.30 \pm 0.06$ & $0.30 \pm 0.06$ & - \\
\hline Herb & $0.44 \pm 0.06$ & $0.34 \pm 0.06$ & $0.38 \pm 0.08$ & $0.34 \pm 0.06$ & - \\
\hline
\end{tabular}

Values are means \pm SEM. TBARs, IL- 6 , and TNF- $a$ were measured only during the eccentric exercise session

CRP C-reactive protein, $C K$ creatine kinase, TBARs thiobarbituric acid reactive substances, IL-6 interleukin-6, TNF- $a$ tumor necrosis factor-a

${ }^{*} P<0.05$ vs. Pre in the same condition. ${ }^{*} P<0.05$ vs. Control or Placebo at the same time point

associated with the corresponding changes in plasma IL6 concentrations after $48 \mathrm{~h}$ post exercise. It is possible to speculate that the supplementation using panax ginseng and salvia miltiorrhiza reduced systemic inflammation induced by eccentric exercise and through such effect,

Table 5 Associations between relative changes (\%) in arterial stiffness and selected biomarkers

\begin{tabular}{lcc}
\hline & $\Delta$ CfPW $24 \mathrm{~h}$ & $\Delta \mathrm{cfPWV} 48 \mathrm{~h}$ \\
\hline$\Delta \mathrm{CK}$ & 0.05 & 0.08 \\
$\mathrm{CRP}$ & 0.17 & 0.21 \\
$\Delta \mathrm{LL}-6$ & 0.11 & $0.46^{*}$ \\
$\Delta \mathrm{TNF}-\mathrm{a}$ & $0.60^{*}$ & $0.57^{*}$ \\
$\Delta$ TBARs & 0.09 & 0.36
\end{tabular}

cfPWV carotid-femoral pulse wave velocity, $C K$ creatine kinase, CRP C-reactive protein, IL-6 interlukin-6, TNF- $a$ tumor necrosis factor-a, TBARs thiobarbituric acid reactive substances

${ }^{*} P<0.05$ minimized the arterial stiffening effects. Our present results using Chinese herbs as "cocktail" anti-oxidants are in accordance with a previous study [43] that supplementation with the mixture of vitamins $\mathrm{C}$ and $\mathrm{E}$ attenuated the IL-6 mRNA expression and CRP response to long-duration muscle contractions in humans.

In addition to central arterial stiffness, endotheliumdependent vascular reactivity was also measured in this study. Eccentric resistance exercise has been shown to impair FMD and linked with the increase in reactive oxygen species and a subsequent reduction in $\mathrm{NO}[7,8]$. In the present study, however, there were no significant reductions in FMD in either the placebo or the herb group. The increases in oxidative stress and inflammation have been documented in association with endothelial dysfunction [44, 45], and anti-oxidant status could play a role in modulating vascular function after eccentric exercise [46]. There were significant increases in inflammatory markers after eccentric exercise in the present study. However, FMD did not change. The discrepancy between our findings and others could be attributed to the difference in exercise mode and measured time points. Acute resistance exercise $[47,48]$ has been shown to reduce FMD, whereas FMD increases after an acute bout of aerobic exercise $[49,50]$. The present study utilized acute downhill running exercise as a mode of eccentric exercise. FMD is also known to display biphasic response after acute exercise in that FMD decreases immediately but increases 1 to $24 \mathrm{~h}$ following exercise and reversed to the baseline in $48 \mathrm{~h}$ [46]. In the study [7] that found reductions in FMD after eccentric resistance exercise, measurements were made $45 \mathrm{~min}$ after exercise. We performed the measurement of FMD at 90 min post exercise. Additionally, the difference in subject characteristics may be another factor since FMD may respond differently following exercise in people of different physical fitness levels $[46,50]$.

There are a number of limitations in the present study that should be mentioned. First, the number of subjects studied is relatively small. Second, even though pharmacological compounds of panax ginseng and salvia miltiorrhiza were identified, it is unknown which compound of the herb supplementation was effective. Additionally, pharmacological interactions between the compounds are also unknown. Lastly, correlations between inflammatory markers and arterial stiffness were found only at selected time points. Additionally, some inflammatory markers (e.g., TNF- $\alpha$ ) did not change with eccentric exercise. Thus, the associations should be interpreted with caution.

\section{Conclusions}

A short-term Chinese herb supplementation incorporating panax ginseng and salvia miltiorrhiza was effective in ameliorating the delayed onset vascular stiffening 
induced by acute eccentric exercise, possibly via the reductions in oxidative stress and systemic inflammation.

\section{Abbreviations}

$\mathrm{BMI}$, body mass index; BP, blood pressure; cfPWV, carotid-femoral pulse wave velocity; $\mathrm{CK}$, creatine kinase; $\mathrm{CRP}, \mathrm{C}$-reactive protein; $\mathrm{HbA1c}$, glycosylated hemoglobin A1c; IL-6, interleukin-6; TBARs, thiobarbituric acid reactive substances; TNF-a, tumor necrosis factor-a; $\mathrm{VO}_{2}$ peak, peak oxygen consumption

\section{Acknowledgements}

We would like to thank Han-Jen Lin from Molecular Biology Laboratory in Department of Animal Science of National Taiwan University, Dr. Hao-Min Cheng and Dr. Chen-Huan Chen from Taipei Veterans General Hospital for their technical assistance on biomarker and hemodynamic analysis.

\section{Funding}

This study was supported by a research grant from the Ministry of Science and Technology in Taiwan (MOST-101-2410-H-002-201-MY2 and MOST 103-2410-H-002 -196-MY2).

\section{Availability of data and materials}

The datasets supporting the conclusions of this article are presented in this paper.

\section{Authors' contributions}

Study concept and design: HL, HT, CL, JL; data collection: HL, TK, CC; data analysis: $\mathrm{HL}, \mathrm{TK}, \mathrm{CC}, \mathrm{CL}$; data interpretation: $\mathrm{HL}, \mathrm{TK}, \mathrm{JL}, \mathrm{HT}$; manuscript drafting: $\mathrm{HL}, \mathrm{HT}$; revising manuscript critically for important intellectual content: HL, TK, CC, CL, JL. HT. All authors have read, edited, approved the final manuscript, and have agreed to be held accountable for all aspects of manuscript in ensuring that questions related to the accuracy or integrity of any part of manuscript are appropriately investigated and resolved.

\section{Competing interests}

The authors declare that they have no competing interests.

\section{Consent for publication}

Not applicable.

\section{Ethics approval and consent to participate}

All subjects gave their written informed consent prior to study participation and procedures were reviewed and approved by the Institutional Review Board of National Taiwan University Hospital.

\section{Author details}

${ }^{1}$ Department of Athletics, National Taiwan University, Taipei, Taiwan. 2Department of Physical Education, National Taiwan Normal University, Taipei, Taiwan. ${ }^{3}$ Physical Education Office, National Taipei University of Technology, Taipei, Taiwan. ${ }^{4}$ Brion Research Institute, Taipei, Taiwan. ${ }^{5}$ School of Chinese Medicine, China Medical University, Taichung City, Taiwan. ${ }^{6}$ Department of Kinesiology and Health Education, The University of Texas at Austin, 2109 San Jacinto Blvd, D3700, Austin, TX 78712, USA.

Received: 17 September 2015 Accepted: 25 May 2016

\section{Published online: 06 June 2016}

\section{References}

1. Peake J, Nosaka K, Suzuki K. Characterization of inflammatory responses to eccentric exercise in humans. Exerc Immunol Rev. 2005;11:64-85.

2. Toft $A D$, Jensen $L B$, Bruunsgaard H, Ibfelt T, Halkjaer-Kristensen J, Febbraio $M$, Pedersen BK. Cytokine response to eccentric exercise in young and elderly humans. Am J Physiol Cell Physiol. 2002;283(1):C289-95.

3. Bruunsgaard H, Galbo H, Halkjaer-Kristensen J, Johansen TL, MacLean DA, Pedersen BK. Exercise-induced increase in serum interleukin-6 in humans is related to muscle damage. J Physiol. 1997;499(Pt 3):833-41.

4. Kano Y, Padilla DJ, Behnke BJ, Hageman KS, Musch TI, Poole DC. Effects of eccentric exercise on microcirculation and microvascular oxygen pressures in rat spinotrapezius muscle. J Appl Physiol. 2005;99(4):1516-22.
5. Kano Y, Sampei K, Matsudo H. Time course of capillary structure changes in rat skeletal muscle following strenuous eccentric exercise. Acta Physiol Scand. 2004;180(3):291-9.

6. Ray CA, Mahoney ET, Hume KM. Exercise-induced muscle injury augments forearm vascular resistance during leg exercise. Am J Physiol. 1998:275(2 Pt 2):H443-7.

7. Choi Y, Akazawa N, Miyaki A, Ra SG, Shiraki H, Ajisaka R, Maeda S. Acute effect of high-intensity eccentric exercise on vascular endothelial function in young men. J Strength Cond Res. In press.

8. Franklin NC, Ali MM, Robinson AT, Norkeviciute E, Phillips SA. Massage therapy restores peripheral vascular function after exertion. Arch Phys Med Rehabil. 2014;95(6):1127-34.

9. Barnes JN, Trombold JR, Dhindsa M, Lin HF, Tanaka H. Arterial stiffening following eccentric exercise-induced muscle damage. J Appl Physiol. 2010:109(4):1102-8.

10. Burr JF, Boulter M, Beck K. Arterial stiffness results from eccentrically biased downhill running exercise. J Sci Med Sport. 2015;18(2):230-5.

11. Yue PY, Mak NK, Cheng YK, Leung KW, Ng TB, Fan DT, Yeung HW, Wong RN. Pharmacogenomics and the yin/yang actions of ginseng: anti-tumor, angiomodulating and steroid-like activities of ginsenosides. Chin Med. 2007;2:6

12. Kang KS, Yokozawa T, Kim HY, Park JH. Study on the nitric oxide scavenging effects of ginseng and its compounds. J Agric Food Chem. 2006;54(7):2558-62.

13. Lu JM, Yao Q, Chen C. Ginseng compounds: an update on their molecular mechanisms and medical applications. Curr Vasc Pharmacol. 2009;7(3):293-302.

14. de Oliveira AC C, Perez AC, Prieto JG, Duarte ID, Alvarez Al. Protection of Panax ginseng in injured muscles after eccentric exercise. J Ethnopharmacol. 2005;97(2):211-4.

15. Estaki M, Noble EG. North American ginseng protects against muscle damage and reduces neutrophil infiltration after an acute bout of downhill running in rats. Appl Physiol Nutr Metab. 2015;40(2):116-21.

16. Yu SH, Huang CY, Lee SD, Hsu MF, Wang RY, Kao CL, Kuo CH. Decreased eccentric exercise-induced macrophage infiltration in skeletal muscle after supplementation with a class of ginseng-derived steroids. PLoS One. 2014; 9(12):e114649.

17. Han JY, Fan JY, Horie Y, Miura S, Cui DH, Ishii H, Hibi T, Tsuneki H, Kimura I. Ameliorating effects of compounds derived from salvia miltiorrhiza root extract on microcirculatory disturbance and target organ injury by ischemia and reperfusion. Pharmacol Ther. 2008;117(2):280-95.

18. Ji XY, Tan BK, Zhu YZ. Salvia miltiorrhiza and ischemic diseases. Acta Pharmacol Sin. 2000;21(12):1089-94.

19. Zhou L, Zuo Z, Chow MS. Danshen: an overview of its chemistry, pharmacology, pharmacokinetics, and clinical use. J Clin Pharmacol. 2005;45(12):1345-59.

20. Cheng TO. Danshen: a versatile Chinese herbal drug for the treatment of coronary heart disease. Int J Cardiol. 2006;113(3):437-8.

21. Tang C, Wu AH, Xue HL, Wang YJ. Tanshinone IIA inhibits endothelin-1 production in TNF-alpha-induced brain microvascular endothelial cells through suppression of endothelin-converting enzyme-1 synthesis. Acta Pharmacol Sin. 2007;28(8):1116-22.

22. Tang C, Xue HL, Bai CL, Fu R. Regulation of adhesion molecules expression in TNF-a-stimulated brain microvascular endothelial cells by Tanshinone lia: Involvement of NF-kb and ROS generation. Phytother Res. 2011;25(3):376-80.

23. Chen YH, Lin SJ, Ku HH, Shiao MS, Lin FY, Chen JW, Chen YL. Salvianolic acid B attenuates VCAM-1 and ICAM-1 expression in TNF-alpha-treated human aortic endothelial cells. J Cell Biochem. 2001;82(3):512-21.

24. Liang X, Chen X, Liang Q, Zhang H, Hu P, Wang Y, Luo G. Metabonomic study of Chinese medicine Shuanglong formula as an effective treatment for myocardial infarction in rats. J Proteome Res. 2011;10(2):790-9.

25. Liang X, Chen X, Wang Y, Liang Q, Wu J, Luo G. Effect of compatibilities and proportions of Shuanglong formula on acute myocardial infarction in rats. Zhongguo Zhong Yao Za Zhi. 2011;36(22):3176-9.

26. China Pharmacopoeia Commission. Pharmacopoeia of the People's Republic of China (Part I). Beijing: Chemical Industry Press; 2010,

27. van Poppel PC, Breedveld P, Abbink EJ, Roelofs H, van Heerde W, Smits P, Lin W, Tan AH, Russel FG, Donders R, et al. Salvia miltiorrhiza root water-extract (danshen) has no beneficial effect on cardiovascular risk factors. A randomized double-blind cross-over trial. PLoS One. 2015; 10(7):e0128695

28. Hu P, Luo GA, Zhao Z, Jiang ZH. Quality assessment of radix Salviae miltiorrhizae. Chem Pharm Bull (Tokyo). 2005;53(5):481-6.

29. American College of Sports Medicine. ACSM's guidelines for exercise testing and prescription. Baltimore: Lippincott Williams \& Wilkins; 2006. 
30. Peake JM, Suzuki K, Wilson G, Hordern M, Nosaka K, Mackinnon L, Coombes JS. Exercise-induced muscle damage, plasma cytokines, and markers of neutrophil activation. Med Sci Sports Exerc. 2005;37(5):737-45.

31. Sacheck JM, Cannon JG, Hamada K, Vannier E, Blumberg JB, Roubenoff R. Age-related loss of associations between acute exercise-induced II-6 and oxidative stress. Am J Physiol Endocrinol Metab. 2006;291(2):E340-9.

32. Clarkson PM, Tremblay I. Exercise-induced muscle damage, repair, and adaptation in humans. J Appl Physiol. 1988;65(1):1-6.

33. Tanaka H, DeSouza CA, Seals DR. Absence of age-related increase in central arterial stiffness in physically active women. Arterioscler Thromb Vasc Biol. 1998;18(1):127-32.

34. Corretti MC, Anderson TJ, Benjamin EJ, Celermajer D, Charbonneau F, Creager MA, Deanfield J, Drexler H, Gerhard-Herman M, Herrington D. Guidelines for the ultrasound assessment of endothelial-dependent flowmediated vasodilation of the brachial artery: a report of the international brachial artery reactivity task force. J Am Coll Cardiol. 2002;39(2):257-65.

35. Baird MF, Graham SM, Baker JS, Bickerstaff GF. Creatine-kinase- and exerciserelated muscle damage implications for muscle performance and recovery. J Nutr Metab. 2012;2012:960363.

36. Armstrong RB, Ogilvie RW, Schwane JA. Eccentric exercise-induced injury to rat skeletal muscle. J Appl Physiol. 1983;54(1):80-93.

37. de Oliveira AC C, Perez AC, Merino G, Prieto JG, Alvarez Al. Protective effects of Panax ginseng on muscle injury and inflammation after eccentric exercise. Comp Biochem Physiol C Toxicol Pharmacol. 2001;130(3):369-77.

38. Jung HL, Kwak HE, Kim SS, Kim YC, Lee CD, Byurn HK, Kang HY. Effects of Panax ginseng supplementation on muscle damage and inflammation after uphill treadmill running in humans. Am J Chin Med. 2011;39(3):441-50.

39. Lin HF, Chou CC, Cheng HM, Tanaka H. Delayed onset vascular stiffening induced by eccentric resistance exercise and downhill running. Clin J Sport Med. In press.

40. Vlachopoulos C, Dima I, Aznaouridis K, Vasiliadou C, loakeimidis N, Aggeli C, Toutouza M, Stefanadis C. Acute systemic inflammation increases arterial stiffness and decreases wave reflections in healthy individuals. Circulation. 2005;112(14):2193-200.

41. Jae SY, Yoon ES, Jung SJ, Jung SG, Park SH, Kim BS, Heffernan KS, Fernhall B. Effect of cardiorespiratory fitness on acute inflammation induced increases in arterial stiffness in older adults. Eur J Appl Physiol. 2013:113(8):2159-66.

42. Yasmin, McEniery CM, Wallace S, Mackenzie IS, Cockcroft JR, Wilkinson IB. C-reactive protein is associated with arterial stiffness in apparently healthy individuals. Arterioscler Thromb Vasc Biol. 2004;24(5):969-74.

43. Fischer CP, Hiscock NJ, Penkowa M, Basu S, Vessby B, Kallner A, Sjoberg LB, Pedersen BK. Supplementation with vitamins $C$ and $E$ inhibits the release of interleukin-6 from contracting human skeletal muscle. J Physiol. 2004;558(Pt 2):633-45.

44. Donato AJ, Eskurza I, Silver AE, Levy AS, Pierce GL, Gates PE, Seals DR. Direct evidence of endothelial oxidative stress with aging in humans: relation to impaired endothelium-dependent dilation and upregulation of nuclear factor-kappaB. Circ Res. 2007;100(11):1659-66.

45. Ferroni P, Basili S, Paoletti V, Davi G. Endothelial dysfunction and oxidative stress in arterial hypertension. Nutr Metab Cardiovasc Dis. 2006:16(3):222-33.

46. Dawson EA, Green DJ, Cable NT, Thijssen DH. Effects of acute exercise on flowmediated dilatation in healthy humans. J Appl Physiol. 2013;115(11):1589-98.

47. Varady KA, Bhutani S, Church EC, Phillips SA. Adipokine responses to acute resistance exercise in trained and untrained men. Med Sci Sports Exerc. 2010;42(3):456-62.

48. Phillips SA, Das E, Wang J, Pritchard K, Gutterman DD. Resistance and aerobic exercise protects against acute endothelial impairment induced by a single exposure to hypertension during exertion. J Appl Physiol. 2011;110(4):1013-20

49. Tinken TM, Thijssen DH, Hopkins N, Black MA, Dawson EA, Minson CT, Newcomer SC, Laughlin MH, Cable NT, Green DJ. Impact of shear rate modulation on vascular function in humans. Hypertension. 2009;54(2):278-85.

50. Harris RA, Padilla J, Hanlon KP, Rink LD, Wallace JP. The flow-mediated dilation response to acute exercise in overweight active and inactive men Obesity (Silver Spring). 2008;16(3):578-84.

\section{Submit your next manuscript to BioMed Central and we will help you at every step:}

- We accept pre-submission inquiries

- Our selector tool helps you to find the most relevant journal

- We provide round the clock customer support

- Convenient online submission

- Thorough peer review

- Inclusion in PubMed and all major indexing services

- Maximum visibility for your research

Submit your manuscript at www.biomedcentral.com/submit
Biomed Central 